\title{
Phosphorus and zinc uptake and their interaction effect on dry matter and chlorophyll content of sweet corn (Zea mays var. Saccharata).
}

\begin{abstract}
Zinc and Phosphorus have antagonistic effect on the absorption and translocation of each other in plants. P-induced $\mathrm{Zn}$ deficiency is more common than $\mathrm{Zn}$-induced $\mathrm{P}$ deficiency because growers commonly apply large amounts of $\mathrm{P}$ fertilizer as compared to $\mathrm{Zn}$ fertilizer. This research was conducted to examine the effect of different levels of $\mathrm{Zn}$ and $\mathrm{P}$ on the yield, $\mathrm{Zn}$ and $\mathrm{P}$ uptake and chlorophyll contents of corn plants. Sweet corn was grown in nutrient culture containing all combinations of $\mathrm{Zn}$ as $\mathrm{ZnSO} 4.7 \mathrm{H} 2 \mathrm{O}$ at levels of 0.0, 5.0, 10.0 and 20.0 $\mathrm{mg} \mathrm{L}-1$ and of P as KH2PO4 at levels of 0.0, 20.0, 40.0 and $80.0 \mathrm{mg} \mathrm{L}-1$. Zn0P20 treatment produced the highest yield and the yields were decreased with $\mathrm{P}$ application in combination with $\mathrm{Zn}$. The lowest dry weight of young corn plants was recorded under Zn0P80 treatment at both harvesting times due to both $\mathrm{Zn}$ deficiency and $\mathrm{P}$ toxicity. Chlorophyll content decreased with high $\mathrm{Zn}$ and $\mathrm{P}$ applications and this can be attributed to the interactions of $\mathrm{Zn}$ and $\mathrm{P}$ with iron in the growth medium. Zn0P80 treatment had the lowest $\mathrm{Zn}$ and the highest $\mathrm{P}$ uptake by shoot at 14 days after transplanting. The study has shown that $\mathrm{Zn}$ deficiency can enhance $\mathrm{P}$ uptake and translocation to such an extent that $\mathrm{P}$ may accumulate to toxic level in leaves. Zn20P80 treatment produced the highest $\mathrm{Zn}$ and $\mathrm{P}$ uptake by roots. $\mathrm{Zn}$ and $\mathrm{P}$ uptake by roots increased with increased $\mathrm{Zn}$ and $\mathrm{P}$ supply.
\end{abstract}

Keyword: Zinc; Phosphorus; Corn; Uptake; Chlorophyll. 